\begin{tabular}{|c|l|}
\hline Title & Low Genetic V ariation of Red-crowned Cranes on Hokkaido Island, Japan, Over the Hundred Y ears \\
\hline Author(s) & A kiyama, Takuya; Momose, Kunikazu; Onuma, Manabu; Matsumoto, Fumio; Masuda, Ryuichi \\
\hline Citation & $\begin{array}{l}\text { Zoological science, 34(3), 211-216 } \\
\text { https://loi.org/10.2108/2s160194 }\end{array}$ \\
\hline Issue Date & 2017-06 \\
\hline Doc URL & http://hdl.handle.net/2115/70660 \\
\hline Type & article \\
\hline File Information & Zs343211-216.pdf \\
\hline
\end{tabular}

Instructions for use 


\title{
Low Genetic Variation of Red-crowned Cranes on Hokkaido Island, Japan, Over the Hundred Years
}

\author{
Takuya Akiyama ${ }^{1}$, Kunikazu Momose ${ }^{2}$, Manabu Onuma ${ }^{3}$, \\ Fumio Matsumoto ${ }^{4}$, and Ryuichi Masuda ${ }^{1,5^{*}}$ \\ ${ }^{1}$ Department of Natural History Sciences, Graduate School of Science, Hokkaido University, \\ Sapporo 060-0810, Japan \\ ${ }^{2}$ Red-crowned Crane Conservancy, Kushiro 085-0036, Japan \\ ${ }^{3}$ Center for Environmental Biology and Ecosystem Studies, National Institute \\ for Environmental Studies, Tsukuba 305-8506, Japan \\ ${ }^{4}$ Kushiro City Zoo, Kushiro 085-0204, Japan \\ ${ }^{5}$ Department of Biological Sciences, Faculty of Science, \\ Hokkaido University, Sapporo 060-0810, Japan
}

\begin{abstract}
The red-crowned crane (Grus japonensis) is recognized internationally as an endangered species. Migratory populations breed in eastern Russia and northeastern China, whereas the resident population inhabits the island of Hokkaido, Japan. Although the population inhabiting Hokkaido had experienced a severe bottleneck by the end of the 19th century, the population size has recovered to about 1500 and continues to increase now thanks to conservation efforts. A previous study reported that no marked genetic differences were seen in the island population, and that the genetic variation of the whole population on Hokkaido was lower than that of the continental population. However, the precise genetic structure of the island population in the past or near present remains unclear. To better understand the spatiotemporal changes in the genetic structure of the island population, we performed mitochondrial DNA (mtDNA) analyses using stuffed specimens (years 1878-2001) and tissue or blood samples (years 1970-2014). We found three haplotypes in the island population, one of which was a novel mtDNA haplotype in 1997 and 2007 samples. In addition, there was no clear difference in the haplotype frequency through the time span. These results suggest that the low genetic variation of the island population persisted for the last hundred years. It is thus nearly impossible for the island population to recover its genetic variation in isolation. Conservation plans for this species should therefore include the promotion of genetic exchanges between the continental and island populations, such as through artificial introduction to Hokkaido.
\end{abstract}

Key words: bottleneck, Grus japonensis, Hokkaido, mitochondrial DNA, red-crowned cranes

\section{INTRODUCTION}

The red-crowned crane (Grus japonensis), listed as an endangered species in the International Union for Conservation of Nature Red List of the Threatened Species (BirdLife International 2013), is distributed in the southeastern Eurasian Continent and Japan. The island population inhabiting Hokkaido Island, Japan, is currently distributed in several limited regions (Meine and Archibald, 1996). The population size had been reduced to near extinction at the end of the 19th century due to the decrease and fragmentation of its habitats and over-hunting. Approximately 20 individuals were rediscovered in the Kushiro marsh in 1926 (Masatomi, 2000), but since that time the crane population inhabiting Hokkaido has recovered to approximately 1500 thanks to conservation activities. Generally, populations that

\footnotetext{
* Corresponding author. E-mail: masudary@sci.hokudai.ac.jp doi:10.2108/zs160194
}

have experienced a bottleneck show manifestations of genetic effects, such as decreased effective population size, fitness, genetic variation, disease resistance, and long-term survival of wild populations in changing environments (Keller and Waller, 2002). Understanding the genetic characteristics of such bottlenecked populations is essential for planning wildlife conservation actions.

Mitochondrial DNA (mtDNA) is a useful tool for phylogenetic, phylogeographic, and population genetic studies because of the rapid rate of evolution, haploidy, and maternal inheritance mode (Sorenson and Quinn, 1998). Although species classification based on mtDNA sequences alone may sometimes result in misunderstanding (Edwards et al., 2005), analyzing mtDNA features is a useful approach for phylogenetic studies.

Hasegawa et al. (1999) reported 18 polymorphic sites in 418 base-pairs (bp) of the control region (CR) 2 in mtDNA to determine haplotypes. Previous mtDNA analyses identified only two haplotypes in the island population, whereas 
another 10 haplotypes were found in the continental population (Hasegawa et al., 1999; Miura et al., 2013; Sugimoto et al., 2015). However, our previous study (Akiyama et al., 2017) reported that the mtDNA of the red-crowned crane contains a duplicated region, including the control region; the existence of orthologs (CR1) was not addressed in previous studies. We therefore focused on the overlapping region to analyze mtDNA haplotypes of red-crowned cranes. In addition, Sugimoto et al. (2015) analyzed microsatellite variation and found no regional genetic differences within the island populations. This also suggested that the genetic structure of the island population has changed as an effect of the increased number of cranes on Hokkaido (Masatomi et al., 2014). However, no direct comparison between the historical and recent genetic structures on the island population of the red-crowned crane has been performed to date.

In the present study, we conducted mtDNA analyses using samples collected between 1878 and 2014. We discuss the lower genetic variation among island populations and spatiotemporal changes in the red-crowned cranes on Hokkaido.

\section{MATERIALS AND METHODS}

\section{Samples and DNA extraction}

Information on stuffed specimens was collected with the cooperation of the Ministry of the Environment. Specimens with clear information on sampling localities in Hokkaido were selected. From these, feather roots were obtained from 17 stuffed specimens preserved in museums or research institutes in Japan (with the oldest samples from the 1870s: Table 1). In addition, we collected 213 samples of blood or tissues obtained from chicks or young birds: 29 samples from the Kushiro City Zoo; 184 samples captured for the bird banding by the Red-Crowned Crane Conservancy or wounded in accidents and rescued by the Kushiro City Zoo. As all the crane individuals mentioned above were captured in Japan, information on capture points or birth locations was available. Total DNA was extracted using the QIAamp DNA Micro Kit (Qiagen) or the DNeasy Blood \& Tissue Kit (Qiagen), following the manufacturer's protocols. To avoid contamination during the analysis of feather samples, DNA extractions were performed using disposable plastic gloves, tubes, and other equipment sterilized by using UV radiation.

\section{Amplification and sequencing of mtDNA}

Because two control region loci (CR1 and CR2) originated from the gene duplication were found in mtDNA of the red-crowned crane (Akiyama et al., 2017), new primers for polymerase chain reaction (PCR) were designed to specifically amplify the CR2 region. Fragment 1 (Fig. 1), containing the complete CR2, was amplified from 210 samples consisting of the stuffed specimens and the contemporary individuals, using primers (primer 1: Lcr1cyt2, 5'-GCC CAT ATT CCA CCC CTA TT-3'; primer 8: H15030, Omote et al., 2013: the primers' positions are shown in Fig. 1), and sequenced by using internal primers (2: L90nd6, 5'-CCA ACC CTC CCA ATA CAA AA-3'; 6: H680cr, 5'-TGT AAG CAC CCG CTG CAC3'; 7: H01251, Omote et al., 2013). PCR amplifications were carried out using the PrimeSTAR GXL DNA Polymerase (Takara) in a volume of $20 \mu$ l containing $70-100 \mathrm{ng}$ of DNA template, $0.4 \mu \mathrm{l}$ of PrimeSTAR GXL Polymerase, $4.0 \mu \mathrm{l}$ of $5 \times$ buffer, $1.6 \mu \mathrm{l}$ of $2.5 \mathrm{mM}$ dNTPs, and $0.3 \mu \mathrm{l}$ of each primer $(20 \mathrm{pmol} / \mu \mathrm{l})$. The reaction conditions were 25 cycles of $98^{\circ} \mathrm{C}$ for $10 \mathrm{sec}, 60^{\circ} \mathrm{C}$ for $5 \mathrm{sec}$, and $68^{\circ} \mathrm{C}$ for $2 \mathrm{~min}$. The amplicons were purified using the QIAquick PCR Purification Kit (Qiagen), and sequenced with the BigDye v3.1 Cycle Sequencing Kit (Life Technologies) and an ABI 3730 DNA automated sequencer (Life Technologies).

\section{Amplification and sequencing of mtDNA with old feather sam- ples \\ Because the stuffed specimens included feather samples more than 100 years old, the genomic DNAs in the old specimens were often highly fragmented, resulting in difficulties in the PCR amplification of long sequences; we therefore designed other prim- ers to amplify the shorter fragments of the CR2 region. Because the $418 \mathrm{bp}$ region was located at the $5^{\prime}$ end of the CR2 including 18 polymorphic sites, it was thought to be of sufficient length to distin-}

Table 1. Profiles of feather samples collected from stuffed specimens examined in the present study.

\begin{tabular}{|c|c|c|c|c|}
\hline Sample ID & Year of sampling & Location of sampling ${ }^{a}$ & mtDNA haplotype & Supplier \\
\hline $1 \mathrm{C2}$ & 1878 & Chitose & Gj2 & Field Science Center for Northern Biosphere, Hokkaido University \\
\hline $2 \mathrm{~K} 2$ & 1927 & Kushiro & Gj2 & Field Science Center for Northern Biosphere, Hokkaido University \\
\hline $3 \mathrm{~K} 2$ & 1960 & Kushiro & Gj2 & Field Science Center for Northern Biosphere, Hokkaido University \\
\hline $4 \mathrm{~K} 2$ & 1971 & Kushiro & Gj2 & Historical Museum of Hokkaido \\
\hline $5 \mathrm{ND} 2$ & 1983 & N.A. & Gj2 & Tsurui Village Furusato Information Center "Minakuru" \\
\hline 6ND2 & 1983 & N.A. & Gj2 & Tsurui Village Furusato Information Center "Minakuru" \\
\hline 7ND1 & 1983 & N.A. & Gj1 & Tsurui Village Furusato Information Center "Minakuru" \\
\hline 8ND2 & 1983 & N.A. & Gj2 & Tsurui Village Furusato Information Center "Minakuru" \\
\hline $9 \mathrm{~K} 2$ & 1986 & Kushiro & Gj2 & $\begin{array}{l}\text { Center for Molecular Biodiversity Research, National Museum of } \\
\text { Nature and Science, Tokyo }\end{array}$ \\
\hline 10B2 & 1987 & Bekkai & Gj2 & Betsukai Town Historical Museum \\
\hline $11 \mathrm{~N} 2$ & 1987 & Nemuro & Gj2 & Nemuro City Museum of History and Nature \\
\hline $12 \mathrm{~A} 2$ & 1988 & Akan & Gj2 & Abiko City Museum of Birds \\
\hline $13 \mathrm{~K} 2$ & 1991 & Kushiro & Gj2 & $\begin{array}{l}\text { Center for Molecular Biodiversity Research, National Museum of } \\
\text { Nature and Science, Tokyo }\end{array}$ \\
\hline $14 \mathrm{~A} 2$ & 1992 & Akan & Gj2 & Miyazaki Prefectural Museum of Nature and History \\
\hline 15ND1 & 1997 & N.A. & Gj1 & Tsurui Village Furusato Information Center "Minakuru” \\
\hline $16 \mathrm{~S} 13$ & 1997 & Shibecha & Gj13 & Abiko City Museum of Birds \\
\hline $17 \mathrm{~K} 2$ & 2001 & Kushiro & Gj2 & Tomakomai City Museum \\
\hline
\end{tabular}

${ }^{a}$ N.A., not available. 
guish haplotypes. This region was divided into two fragments, and each fragment was amplified by an independent $P C R$ using primers (2: L90nd6; 4: H196cr2, 5'-ATT GGG TTG GAC AGT GGT TG-3') for the fragment I (286 bp), and the primers (3: L128cr2, 5'-CAT TCA ATG TAA AAG ACA CAT CAC A-3'; 5: H463cr, Akiyama et al., 2017) for fragment II (381 bp). The PCR amplifications were performed in a volume of $20 \mu \mathrm{l}$ containing 20-60 ng of DNA template, $0.4 \mu \mathrm{l}$ of PrimeSTAR GXL DNA Polymerase, $4.0 \mu \mathrm{l}$ of $5 \times$ buffer, $1.6 \mu \mathrm{l}$ of 2.5
$\mathrm{mM}$ dNTPs, $0.2 \mu \mathrm{l}$ of $20 \mathrm{mg} / \mathrm{ml}$ bovine serum albumin (BSA, Roche Diagnostics), and $0.3 \mu \mathrm{l}$ of each primer $(20 \mathrm{pmol} / \mu \mathrm{l})$. The BSA binds to various PCR inhibitors possibly included in old samples. The PCR conditions for the old samples were 35 cycles of $98^{\circ} \mathrm{C}$ for 10 $\mathrm{sec}, 60^{\circ} \mathrm{C}$ for $5 \mathrm{sec}$, and $68^{\circ} \mathrm{C}$ for $20 \mathrm{sec}$. The PCR products were purified and sequenced as described above.

\section{Analyses of mtDNA sequences}

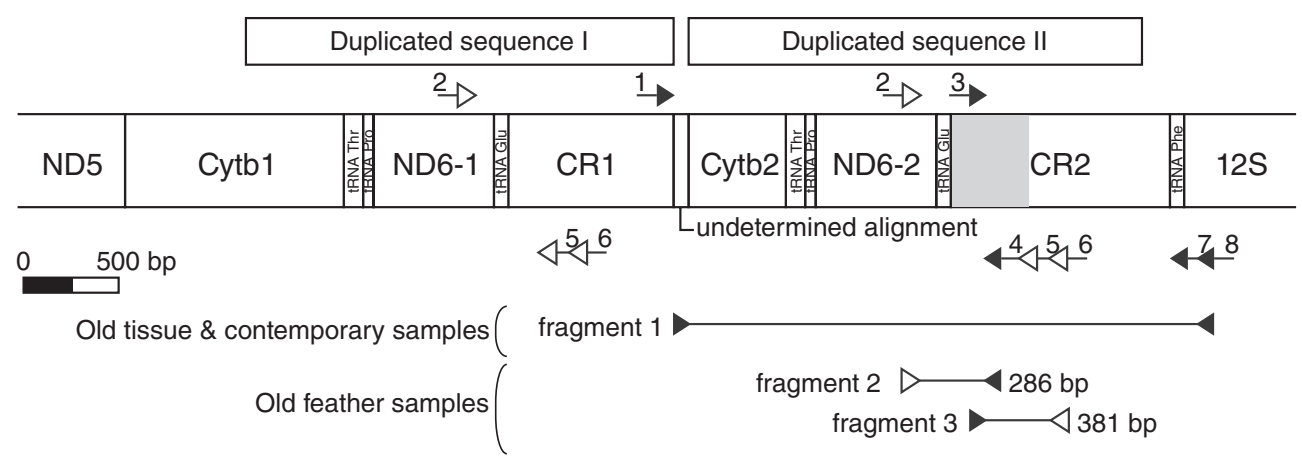

Fig. 1. A scheme of mtDNA gene order around the duplicated region and position at which a primer was used. The gray box indicates the target region (440 bp) for haplotyping the island population of the red-crowned crane (Grus japonensis). For old tissues and contemporary samples, fragment 1 was PCR-amplified. For old feather samples, fragments 2 and 3 were PCR-amplified. Arrows with number show the primer positions. Closed arrows indicate primers annealing the specialized locations in the duplicated region. Abbreviations for genes or region are as follows: ND5, NADH dehydrogenase subunit 5; Cytb1 and Cytb2, cytochrome b1 and cytochrome b2; ND6, NADH dehydrogenase subunit $6 ; 12 S$, 12SrRNA; CR1 and CR2, control regions 1 and control regions 2; Thr, tRNA-Threonine; Pro, tRNAProline; Glu, tRNA-Glutamic acid; Phe, tRNA- Phenylalanine.
The mtDNA sequences were aligned with MEGA v5.0 (Tamura et al., 2011). To investigate the relationships among mtDNA haplotypes, a parsimony network of haplotypes was generated using TCS v1.21 (Clement et al., 2000). Ten additional haplotypes reported in previous studies (Hasegawa et al., 1999; Miura et al., 2013b) were obtained from the DNA Data Bank of Japan (DDBJ) (accession numbers $A B 714138-A B 714140$ for $\mathrm{Gj} 3-5$; and AB669093-AB669095 for Gj10-12; Table 2). For further study on the evolutional relationships among mtDNA haplotypes, we reconstructed a phylogenetic tree by Bayesian inference $(\mathrm{BI})$. This analysis used the complete CR2 sequences (haplotypes Gj1-5, Gj9-13 and that of Grus leucogeranus as an outgroup;

Table 2. Alignment of control region 2 (CR2; $1165 \mathrm{bp})$ haplotypes of the red-crowned crane. Only substitutions are shown. Nine haplotypes (Gj1-Gj9) were reported by Hasegawa et al. (1999), and three haplotypes (Gj10-Gj12) were reported by Miura et al. (2013b). Haplotype Gj13 (bold) was newly identified in the present study. Nucleotides identical to those in Gj1 are indicated by dots; nucleotides different from Gj1 are shown by letters. Dashes show no sequence information (not gaps.) Sequence data were not available at positions 550-1000 for haplotypes Gj5-Gj9.

\begin{tabular}{|c|c|c|c|c|c|c|c|c|c|c|c|c|c|c|c|c|c|c|c|c|c|c|c|c|c|c|}
\hline Haplotype & 23 & & & & & & 166 & 190 & & & & 25 & 274 & 318 & 32 & & 407 & 440 & 550 & 562 & 622 & 808 & 836 & 1000 & Reference & $\begin{array}{c}\text { accession } \\
\text { nos. }\end{array}$ \\
\hline Gj1 & $T$ & A & C & A & A & $\mathrm{T}$ & C & C & C & $\mathrm{G}$ & $\mathrm{G}$ & A & C & $\mathrm{T}$ & $\mathrm{G}$ & A & C & C & $\mathrm{T}$ & C & C & C & $\mathrm{G}$ & A & $\begin{array}{l}\text { Hasegawa } \\
\text { et al. } 1999\end{array}$ & AB714136 \\
\hline Gj2 & . & . & . & . & . & . & $\mathrm{T}$ & . & $\mathrm{T}$ & A & A & . & . & ${ }^{\circ}$ & A & G & $\mathrm{T}$ & $\mathrm{T}$ & C & $\mathrm{T}$ & . & $\mathrm{T}$ & A & $\mathrm{G}$ & $\begin{array}{l}\text { Hasegawa } \\
\text { et al. } 1999\end{array}$ & AB714137 \\
\hline Gj3 & . & . & . & . & . & C & $\mathrm{T}$ & . & . & . & A & $\mathrm{G}$ & . & C & . & . & . & $\mathrm{T}$ & C & . & $\mathrm{T}$ & $\mathrm{T}$ & . & $\mathrm{G}$ & $\begin{array}{l}\text { Hasegawa } \\
\text { et al. } 1999\end{array}$ & AB714138 \\
\hline $\mathrm{Gj} 4$ & . & . & . & $\mathrm{G}$ & . & . & $\mathrm{T}$ & . & . & . & A & . & . & . & . & . & . & $\mathrm{T}$ & C & . & . & . & . & $\mathrm{G}$ & $\begin{array}{l}\text { Hasegawa } \\
\text { et al. } 1999\end{array}$ & AB714139 \\
\hline Gj5 & . & . & . & . & . & . & $\mathrm{T}$ & . & . & . & A & . & . & . & . & $\mathrm{G}$ & . & $\mathrm{T}$ & C & . & . & $\mathrm{T}$ & . & $\mathrm{G}$ & $\begin{array}{l}\text { Hasegawa } \\
\text { et al. } 1999\end{array}$ & AB714140 \\
\hline Gj6 & . & . & . & . & . & . & $\mathrm{T}$ & . & . & & A & . & . & . & . & & . & $\mathrm{T}$ & - & - & - & - & - & - & $\begin{array}{l}\text { Hasegawa } \\
\text { et al. } 1999\end{array}$ & - \\
\hline Gj7 & . & . & . & . & . & . & $\mathrm{T}$ & . & . & $A$ & A & . & . & . & A & $\mathrm{G}$ & . & $\mathrm{T}$ & - & - & - & - & - & - & $\begin{array}{l}\text { Hasegawa } \\
\text { et al. } 1999\end{array}$ & - \\
\hline Gj8 & . & . & . & . & . & . & $\mathrm{T}$ & . & . & . & A & . & $\mathrm{T}$ & . & . & $\mathrm{G}$ & . & $\mathrm{T}$ & - & - & - & - & - & - & $\begin{array}{l}\text { Hasegawa } \\
\text { et al. } 1999\end{array}$ & - \\
\hline Gj9 & . & . & . & . & . & . & $\mathrm{T}$ & . & . & . & A & $\mathrm{G}$ & . & C & . & . & . & $\mathrm{T}$ & - & - & - & - & - & - & $\begin{array}{l}\text { Hasegawa } \\
\text { et al. } 1999\end{array}$ & - \\
\hline Gj10 & C & $\mathrm{T}$ & A & . & . & . & $\mathrm{T}$ & . & . & . & A & . & . & . & . & $\mathrm{G}$ & . & $\mathrm{T}$ & C & . & . & $\mathrm{T}$ & . & $\mathrm{G}$ & $\begin{array}{c}\text { Miura } \\
\text { et al. 2013a }\end{array}$ & AB669093 \\
\hline Gj11 & . & . & . & . & . & . & . & $\mathrm{T}$ & . & . & A & . & . & . & . & $\mathrm{G}$ & . & $\mathrm{T}$ & C & $\mathrm{T}$ & . & $\mathrm{T}$ & . & $\mathrm{G}$ & $\begin{array}{c}\text { Miura } \\
\text { et al. 2013a }\end{array}$ & AB669094 \\
\hline Gj12 & . & . & . & . & $\mathrm{G}$ & . & $\mathrm{T}$ & . & . & $A$ & $A$ & . & . & . & $A$ & $\mathrm{G}$ & . & $\mathrm{T}$ & C & $\mathrm{T}$ & . & $\mathrm{T}$ & . & $\mathrm{G}$ & $\begin{array}{c}\text { Miura } \\
\text { et al. 2013a }\end{array}$ & AB669095 \\
\hline Gj13 & . & . & . & . & . & 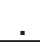 & . & . & . & . & . & . & . & . & . & . & . & $\mathbf{T}$ & C & . & . & . & . & . & This study & LC129041 \\
\hline
\end{tabular}


LC114478) aligned with the MUSCLE algorithm (Edgar, 2004). The best-fit nucleotide substitution models under the Bayesian information criterion $(\mathrm{BIC})$ for $\mathrm{BI}$ analysis were estimated using Kakusan4 (Tanabe, 2007, 2011). The BI analysis was executed with MrBayes v3.2 (Ronquist and Huelsenbeck, 2003). Parameter spaces were explored in the analysis using one cold chain and three incrementally heated chains; each analysis was run for one million generations, with sampling every 1000 generations, and first $25 \%$ of saved trees were discarded as burn-in. To verify convergence of the Metropolis-coupled Markov chain Monte Carlo (MCMCMC) process, two simultaneous runs were continued until the standard deviation of split frequencies between the chains was lower than 0.01 . Convergence of MCMCMC parameter estimates was confirmed using Tracer v1.6 (http://beast.bio.ed.ac.uk/Tracer). Effective sample size values of all parameters were at least 200 . The BI trees were edited using FigTree v1.4.2 (http://tree.bio.ed.ac.uk.software/ figtree/). To visualize the spatiotemporal changes of distribution and frequencies of mtDNA haplotypes, we plotted haplotypes on a map of Hokkaido over the last several decades.

\section{RESULTS}

\section{Relationships of mtDNA haplotypes}

Partial ( 440 bp containing the 418 bp region) or complete (1162 bp) sequences of the mtDNA CR2 were determined on the samples, including 17 stuffed specimens (collected in 1878-2001) and 213 tissue or blood samples (collected in 1970-2014). In the present study, three haplotypes (Gj1, Gj2 and $\mathrm{Gj} 13$ ) were identified from the island population. Haplotypes $\mathrm{Gj} 1$ and $\mathrm{Gj} 2$ were frequently found among individuals of the island population (Hasegawa et al., 1999; Miura et al., 2013a; Sugimoto et al., 2015). In contrast, in the present study, haplotype Gj13 was identified for the first time as a novel haplotype from a single stuffed specimen and one contemporary sample. The obtained sequence data were deposited to the DDBJ/EMBL/GenBank under accession no. LC129041. This new haplotype Gj13 had only two substitutions from haplotype $\mathrm{Gj} 1$ at nucleotide positions 440 and 550 , both of which were highly polymorphic sites within the CR2 (Table 2).

Figure 2 shows a parsimony network of the mtDNA haplotypes based on the 5' end of $440 \mathrm{bp}$ in the CR2. Haplotype Gj13 was a missing link between Gj1 and Gj6. Haplotypes Gj3-9 were found in the continental population (Hasegawa et al., 1999), and haplotypes Gj10-12 were found in the feather samples of field-collected cranes in the Honshu main island of Japan, which may have been derived from continental individuals flying to Japan; no information was available on whether the individuals were wild or bred (Miura et al., 2013b). As the previous study (Hasegawa et al., 1999), the three haplotypes identified from only the island population (Gj1, Gj2 and $\mathrm{Gj} 13$ ) and ten haplotypes identified from only continental individuals (Gj3-12) formed a common cluster. In addition, continental haplotypes (Gj5, Gj6 and Gj7) were positioned between the Hokkaido haplotypes Gj2 and Gj13 and other continental haplotypes connected to the Gj5, Gj6 or Gj7 (Fig. 2). Figure 3 shows the phylogenetic relationships among haplotypes, reconstructed by the $1141 \mathrm{bp}$ of CR2. The optimal nucleotide substitution model determined by BIC4 (sample size = the number of sites) using Kakusan4 was HKY85+Gamma. Haplotypes from the island population were polyphyletic, whereas Gj1 and Gj13 formed a well-supported clade, and Gj2 formed a clade with Gj12,

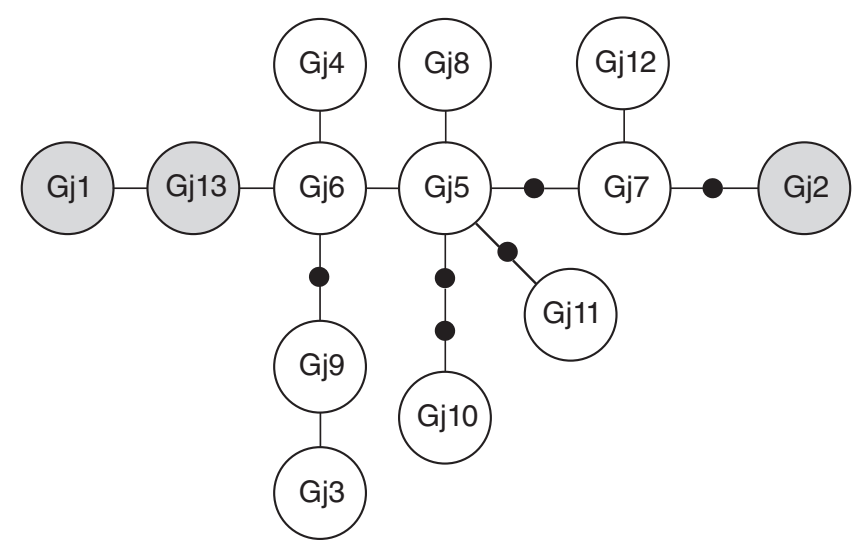

Fig. 2. Parsimony network of $\mathrm{CR} 2$ haplotypes from the redcrowned crane. Gray circles (Gj1, Gj2 and Gj13) show haplotypes identified from the island population in the present study. Open circles indicate previously reported continental haplotypes (Hasegawa et al., 1999; Miura et al., 2013a) and closed circles indicate putative haplotypes. Each line between circles indicates one base substitution.

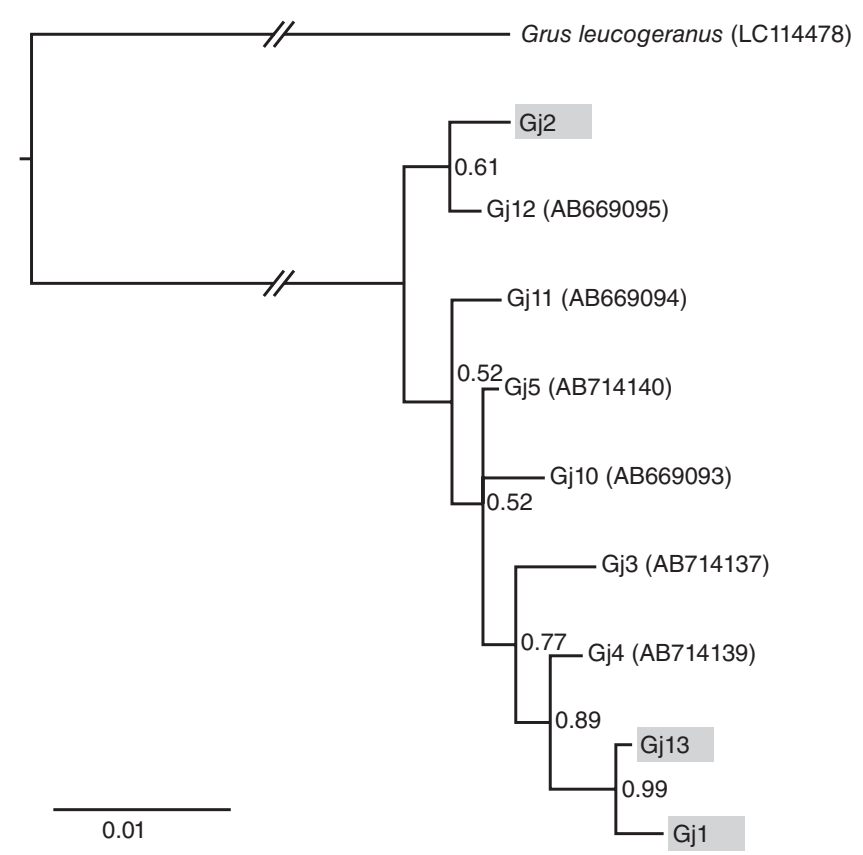

Fig. 3. Bayesian tree based on the CR2 sequences. Fifty percent majority-rule consensus trees inferred from CR2 sequences (1141 bp) of different haplotypes. Haplotypes with gray backgrounds were found in the island population in the present study. GenBank accession numbers of the previously reported haplotype sequences are indicated in parentheses. Numbers on node show the posterior probabilities values. The scale bar indicates the number of substitutions per nucleotide site.

which was thought to be a continental haplotype.

\section{Frequencies of mtDNA haplotypes in the island popula- tion}

The mtDNA haplotype frequencies in the island populations were as follows: $8.7 \%$ (20/230 individuals) for Gj1; $90.4 \%$ (208/230 individuals) for Gj2; 0.9\% (2/230 individuals) for Gj13. Figure 4 shows the transition of the mtDNA haplo- 

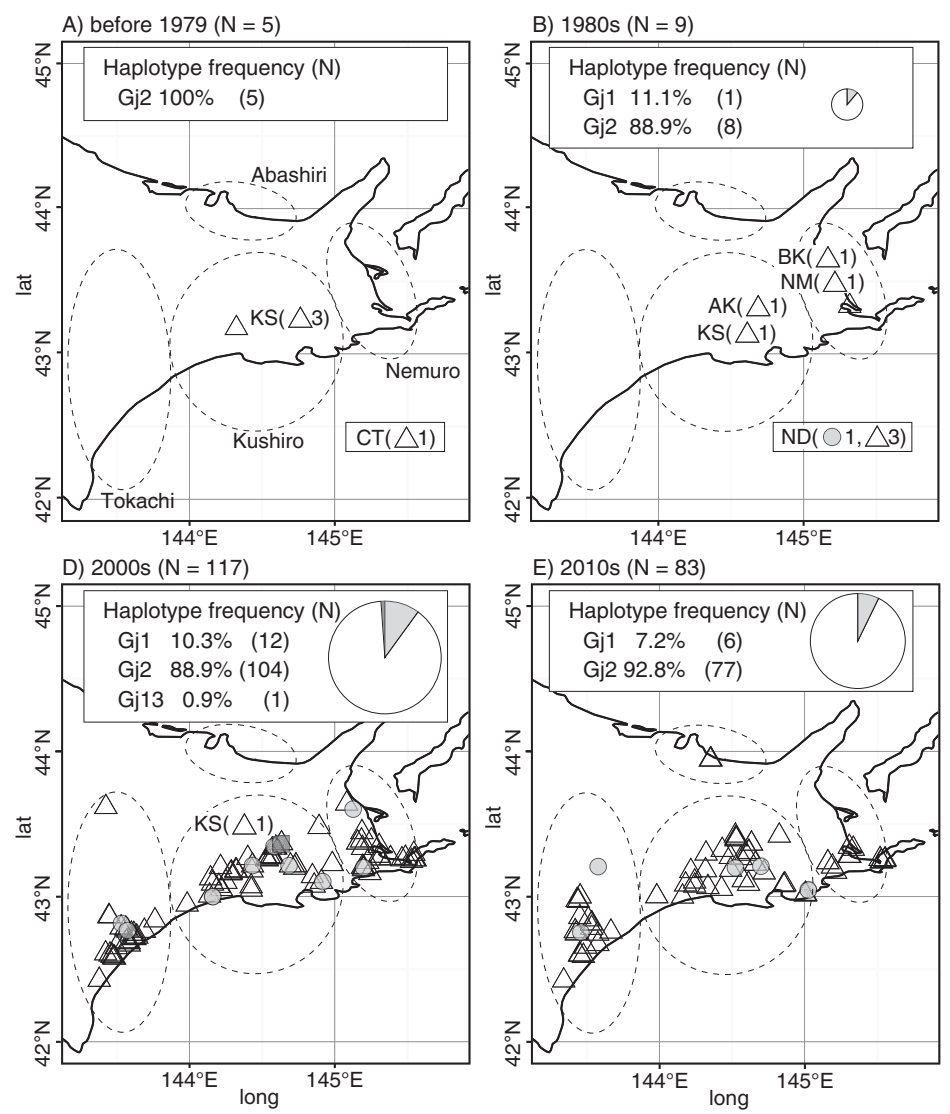

Fig. 4. Haplotype frequencies and distribution of mtDNA haplotypes in the island population through 1878-2014: (A) before 1979, (B) 1980s, (C) 1990s, (D) 2000s, (E) 2010s, respectively. Crcles with dotted lines indicate four areas: Abashiri, Kushiro, Nemuro and Tokachi. MtDNA haplotypes were shown as follows: gray circle for Gj1; triangle for Gj2; dark gray square for Gj13. Abbreviations of sampling locations for stuffed specimens (A) are as follows: CT, Chitose; KS, Kushiro; BK, Bekkai; NM, Nemuro; AK, Akan; SB, Shibecha; ND, No data. The frequencies of haplotypes are visualized by pie charts colored by gray (Gj1), white (Gj2) and dark gray (Gj13).
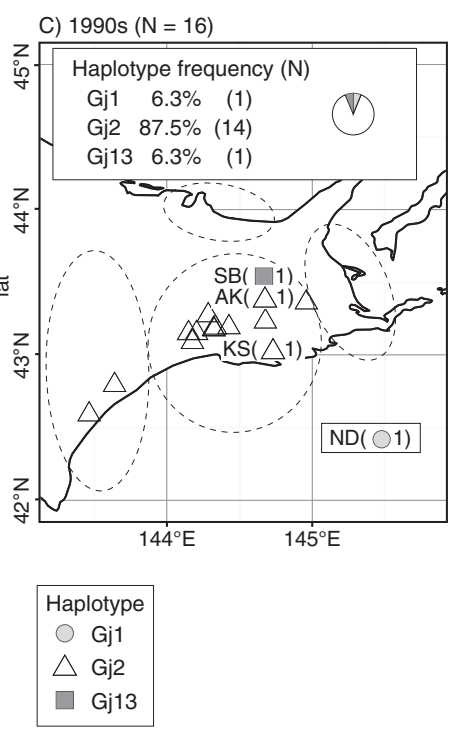

island population. Nevertheless, it is uncertain whether Gj13 remains in the modern population, as it has not been identified from any samples collected after 2007. This haplotype could have disappeared due to inbreeding or genetic drift after the bottleneck. Haplotype Gj2 was found most frequently among samples, irrespective of region and period (Fig. 4). The higher frequencies of haplotypes Gj1 and Gj2 were in agreement with those in previous reports (Miura et al., 2013a; Sugimoto et al., 2015). Sugimoto et al. (2015) reported no apparent spatial genetic structures in the current island population from microsatellite and mtDNA analyses. The present study also showed a low

type distribution in the island population over the past several decades, although information on the old feather samples such as capture areas and birth years was incomplete. Haplotype Gj2 occurred more frequently in all time-spans, and this haplotype was widespread in eastern Hokkaido. In addition, Gj1 was also found in most regions in Hokkaido through 1878-2014, except in few occasions such as Nemuro in the 2010s (Fig. 4E) and Abashiri across all timespans. The novel haplotype Gj13 was identified from one stuffed specimen sample obtained in Kushiro in 1997 and one contemporary sample, also obtained in Kushiro in 2007. In most contemporary samples in the 2010s (Fig. 4E), no additional novel haplotypes were found.

\section{DISCUSSION}

\section{Frequencies of mtDNA haplotypes in the island popula- tion}

In the present study, three CR2 haplotypes were identified from samples of the island population over the past several decades. No common haplotypes between the continental and island populations were found. Haplotype Gj13 found in only two samples of Hokkaido was positioned at a missing haplotype near haplotype Gj1 in the haplotype network, indicating that Gj13 is specific but infrequent in the genetic variation of the island population, and that this state has continued for about 100 years. The lower levels of genetic variation in the red-crowned crane of Hokkaido may have resulted from the population recovery from a very small number of individuals over the past few decades, as reported by Masatomi (2000). Unfortunately, the number of historical stuffed specimens samples examined in the present study was too low to assess the effects of the past population decrease in Hokkaido. It is necessary to analyze older samples, such as archaeological remains or greater numbers of historical samples of the red-crowned crane for the investigation of the following points: (1) whether there were any common haplotypes in mtDNA between the continental and island populations in the past; (2) detailed genetic structure changes during and before the population decline.

\section{Evolutionary relationships among mtDNA haplotypes of the red-crowned crane}

The haplotypes of the red-crowned crane mtDNA found in the island population did not form a single clade. This suggests that the population was divided after the divergence of the haplotypes, and it is possible that the island population had other haplotypes and then lost some of them through a bottleneck. To investigate the process of the genetic struc- 
ture formation, the migration rate and the diverged period between the continental and island population, it is necessary to precisely compare the genetic variation of the island population with those of the continental population.

In a previous study on the structure of female unison calls (Archibald, 1976), the island population has diverged from the continental population at a subspecies level. However, the phylogenetic analysis of the present study shows that the mtDNA haplotypes found from the two populations were not largely differentiated. Although it was reported that some individuals flew from the continent to Japan in 20082011 (Miura et al., 2013b), the present study suggests no gene flow (Fig. 4D, E). Genetic exchange between two populations may improve the low genetic variation in Hokkaido. It seems difficult for the island population, in which genetic structure was equalized and genetic variation was low, would be able to significantly recover the genetic variation on its own. Accordingly, if mating between the continental and island individuals is possible; conservation plans might include the artificial introduction of continental individuals to Hokkaido for the recovery of genetic variation in the island population. If that is pursued, however, it will be important to consider that encounters between individuals from different habitats carry the risk of transmitting pathogens derived from the each habitat. Because red-crowned cranes live in narrow regions in Hokkaido at a high density, there is a serious concern about outbreaks of infectious disease. In future conservation efforts, it is important to promote an expansion of its distribution by artificial movement and dispersal in order to reduce the risk of morbidity and population extinction. In addition, further studies on functionally important genes, such as major histocompatibility complex genes, could be useful for evaluating adaptive genetic variation in the island population and monitoring the genotypes of the continental individual to support potential introduction strategies.

\section{ACKNOWLEDGMENTS}

We thank Dr. Matthew H. Dick, Dr. Yoshinori Nishita, and Dr. Tetsuo I. Kohyama for invaluable comments and editing the manuscript. The Ministry of the Environment originally obtained the samples through conservation activities for the red-crowned crane. Tissue samples were provided from the Kushiro City Zoo (Ryoji Shimura). Feather samples were provided by the Hokkaido University Field Science Center for Northern Biosphere; Shiretoko Museum (Takahiro Murakami); Historical Museum of Hokkaido (Shigehisa Hori); Tsurui Village Furusato Information Center "Minakuru" (Yusuke Ishizuka); Betsukai Town Historical Museum (Kazuto Isuwatari); Nemuro City Museum of History and Nature (Norihisa Kondo); Abiko City Museum of Birds (Ken-ichi Tokita); Miyazaki Prefectural Museum of Nature and History (Hideki Fukushima); and Tomakomai City Museum (Aiko Kodama). This study was supported in part by the Environment Research and Technology Development Fund of the Ministry of the Environment, Japan (No. D-1201), and the research grant of the Akiyama Life Science Foundation, Japan.

\section{COMPETING INTERESTS}

The authors have no competing interests to declare.

\section{AUTHOR CONTRIBUTIONS}

$\mathrm{FM}, \mathrm{KM}, \mathrm{MO}$ and TA performed sample collection and DNA preparation. TA analyzed data, and discussed with RM. TA and RM wrote the manuscript. All authors read, discussed and approved the final manuscript.

\section{REFERENCES}

Akiyama T, Nishida C, Momose K, Onuma M, Takami K, Masuda R (2017) Gene duplication and concerted evolution of mitochondrial DNA in crane species. Mol Phylogenet Evol 106: 158-163

Archibald GW (1976) Crane taxonomy as revealed by the unison call. Proc 1975 Int Crane Workshop 1, pp 225-251

Clement M, Posada D, Crandall KA (2000) TCS: A computer program to estimate gene genealogies. Mol Ecol 9: 1657-1659

Edgar RC (2004) MUSCLE: Multiple sequence alignment with high accuracy and high throughput. Nucleic Acids Res 32: 17921797

Edwards SV, Kingan SB, Calkins JD, Balakrishnan CN, Jennings WB, Swanson WJ, Sorenson MD (2005) Speciation in birds: genes, geography, and sexual selection. Proc Natl Acad Sci U S A 102: 6550-6557

Hasegawa O, Takada S, Yoshida MC, Abe S (1999) Variation of mitochondrial control region sequences in three crane species, the red-crowned crane Grus japonensis, the common crane G. grus and the hooded crane G. monacha. Zoolog Sci 16: 685692

Keller LF, Waller DM (2002) Inbreeding effects in wild populations. Trends Ecol Evol 17: 230-241

Masatomi H (2000) The all of Tancho. Hokkaido Shinbun Press, Sapporo (in Japanese)

Masatomi H, Momose K, Koga K, Inose M, Matsumoto F, Tomiyama N (2014) Number of the Tancho Grus japonensis living in Hokkaido in mid-winter of 2012. Bull Akan Intern Crane Center 11: 3-17 (in Japanese)

Meine CD, Archibald GW (1996) The cranes: status survey and conservation action plan. IUCN, Gland, Switzerland, and Cambridge, UK

Miura Y, Shiraishi J, Shiomi A, Kitazawa T, Hiraga T, Matsumoto F, et al. (2013a) Origin of three red-crowned cranes Grus japonensis found in northeast honshu and west Hokkaido, Japan, from 2008 to 2012. J Vet Med Sci 75: 1241-1244

Miura Y, Shiomi A, Shiraishi J, Makita K, Asakawa M, Kitazawa T, et al. (2013b) Large-scale survey of mitochondrial D-loop of the red-crowned crane Grus japonensis in Hokkaido, Japan by convenient genotyping method. J Vet Med Sci 75: 43-47

Ronquist F, Huelsenbeck JP (2003) MrBayes 3: Bayesian phylogenetic inference under mixed models. Bioinformatics 19: 15721574

Sorenson MD, Quinn TW (1998) Numts: a challenge for avian systematics and population biology. Auk 115: 214-221

Sugimoto T, Hasegawa O, Azuma N, Masatomi H, Sato F, Matsumoto F, et al. (2015) Genetic structure of the endangered red-crowned cranes in Hokkaido, Japan and conservation implications. Conserv Genet 16: 1395-1401

Tamura K, Peterson D, Peterson N, Stecher G, Nei M, Kumar S (2011) MEGA5: molecular evolutionary genetics analysis using maximum likelihood, evolutioanry distance, and maximum parsimony methods. Mol Biol Evol 28: 2731-2739

Tanabe AS (2007) Kakusan: a computer program to automate the selection of a nucleotide substitution model and the configuration of a mixed model on multilocus data. Mol Ecol Notes 7: 962-964

Tanabe AS (2011) Kakusan4 and Aminosan: two programs for comparing nonpartitioned, proportional and separate models for combined molecular phylogenetic analyses of multilocus sequence data. Mol Ecol Resour 11: 914-921

(Received November 13, 2016 / Accepted February 13, 2017) 